\title{
ELEMEN-ELEMEN ADAPTASI DALAM FILEM TOMBIRUO: PENUNGGU RIMBA (TPR)
}

\author{
SUDIRMAN KIFFLI* \\ NURUL AFINI ROSLIN MOHD SAUFI** \\ sudirman.k@umk.edu.my*,nurulafiniroslin@gmail.com**
}

\begin{abstract}
Abstrak
Penghasilan filem adaptasi adalah salah satu kaedah dalam memastikan kesinambungan karya-karya sastera agar sentiasa berkembang dalam pelbagai medium. Menerusi kajian ini, penelitian diberikan terhadap aspek-aspek adaptasi yang terdapat dalam penghasilan filem Tombiruo: Penunggu Rimba yang diadaptasi daripada novel Tombiruo Penunggu Rimba karya Ramlee Awang Murshid. Sebagai sebuah filem adaptasi yang masih baharu, kajian dan penyelidikan mengenai filem Tombiruo Penunggu Rimba (TPR) masih belum banyak dianalisis. Oleh hal yang sedemikian, penelitian telah dilakukan ke atas filem TPR dengan menerapkan pendekatan daripada Linda Hutcheon (2006). Empat aspek yang menjadi fokus kajian ini ialah (1) sumber dan cara adaptasi, (2) tujuan adaptasi, (3) kumpulan atau penonton sasaran dan (4) konteks. Dapatan kajian menunjukkan keempat-empat elemen berkenaan diterapkan dengan baik di dalam penghasilan filem adaptasi TPR oleh pihak pembikin filem. Keadaan ini dikukuhkan dengan pelbagai peristiwa dan situasi seperti dipaparkan di dalam filem berkenaan yang secara tidak langsung memberikan kesan yang amat mendalam kepada khalayak yang menonton filem ini. Kesemua elemen adaptasi ini boleh membantu pihak pembikin filem untuk menghasilkan sebuah filem adaptasi dengan lebih baik.
\end{abstract}

Kata Kunci: cara adaptasi, filem adaptasi, konteks, kumpulan penonton, tujuan adaptasi 


\title{
THE ELEMENTS OF ADAPTATION IN TOMBIRUO: PENUNGGU RIMBA (TPR)
}

\author{
SUDIRMAN KIFFLI* \\ NURUL AFINI ROSLIN MOHD SAUFI** \\ sudirman.k@umk.edu.my*, nurulafiniroslin@gmail.com**
}

\begin{abstract}
The production of adaptation films is one of the methods in ensuring the continuity of literary works so that they are constantly evolving in various mediums. Through this study, research focuses on the aspects of adaptation found in the production of the film Tombiruo: Penunggu Rimba (TPR) adapted from the novel with the same title by Ramlee Awang Murshid. As an adaptation film that is still considered as new, the TPR film has not been much analyzed. As such, a study was conducted on TPR film by applying the approach introduced by Linda Hutcheon (2006). This study focuses on four aspects namely (1) source and method of adaptation, (2) purpose of adaptation, (3) target group or audience and (4) context. The results show that the four aspects are well applied in the production of TPR by the filmmakers. This situation is reinforced by various events and situations as shown in the film itself which indirectly gives a very profound effect to the audience watching this film. All these elements of adaptation can help the filmmaker to produce a better adaptation film.
\end{abstract}

Keywords: Context, group of audience, film adaptation, method of adaptation, purpose of adaptation 
Pengadaptasian sesebuah karya sastera ke dalam bentuk filem bukanlah sesuatu perkara yang tidak lazim dalam dunia kreatif pada hari ini. Terdapat banyak filem yang telah dihasilkan daripada adaptasi sesebuah karya sastera tidak kira karya sastera dalam bentuk cerita rakyat, dongeng, mitos, legenda, cerita pendek mahupun pengadaptasian daripada sesebuah novel. Fenomena pengadaptasian ini telah berlaku sejak puluhan tahun dahulu. Proses pengadaptasian ini adalah sebahagian daripada peralihan kaedah penceritaan selepas munculnya bentuk hiburan dalam medium perfileman. Perkara ini disokong dengan pandangan daripada McFarlane, B. (1996) yang menyatakan bahawa,

As soon as the cinema began to see itself as a narrative entertainment, the idea of ransacking the novel--that already established repository of narrative fiction-for source material got underway, and the process has continued more or less unabated for ninety years. Film-makers' reasons for this continuing phenomenon appear to move between the poles of crass commercialism and high-minded respect for literary works.

Perkara ini dapat dikesan melalui jumlah filem-filem adaptasi yang dihasilkan. Sebagai contoh, pusat penghasilan filem terbesar dunia iaitu Hollywood memperlihatkan banyak filem yang dihasilkan daripada adaptasi karya-karya sastera. Antaranya adalah seperti filem The Help arahan Tate Taylor yang diadaptasikan daripada sebuah novel dengan tajuk yang sama karya Kathryn Stockett. Kemudian, filem Harry Potter yang telah diadaptasikan daripada penulis popular J.K Rowling serta banyak lagi filem-filem Hollywood lain yang diadaptasikan daripada sebuah karya sastera. Menurut Davies (2011), dianggarkan lebih kurang 65\% daripada filem-filem yang dihasilkan adalah adaptasi daripada karya-karya sastera. Keadaan ini menunjukkan betapa adaptasi memainkan peranan yang besar dalam mengangkat karya-karya sastera ke peringkat yang lebih tinggi. Lebih menarik lagi apabila filem-filem yang dihasilkan daripada adaptasi karya sastera ini banyak menerima anugerah berprestij dalam perfileman iaitu anugerah Oscar. Antaranya adalah filem Hamlet yang diadaptasikan daripada drama Hamlet karya William Shakespeare yang memenangi anugerah berkenaan pada tahun 1949, Around The World in 80 Days yang diadaptasi daripada novel Around The Word in Eighty Days karya Jules Verne yang memenangi anugerah tersebut pada tahun 1957 dan banyak lagi filem lain yang turut diadaptasikan daripada karya sastera. Keadaan ini membuktikan betapa sesebuah filem yang dihasilkan daripada adaptasi sesebuah karya sastera mempunyai unsur naratif yang sangat kukuh untuk membantu pihak pembikin filem menghasilkan filem yang mempunyai kualiti yang baik.

Selain Hollywood, pihak pembikin filem di negara-negara lain turut banyak menghasilkan filem adaptasi daripada karya-karya sastera. Dunia perfileman kedua terbesar dunia iaitu Bollywood misalnya juga banyak menghasilkan filem daripada adaptasi sesebuah teks sastera. Antara filem adaptasi yang dihasilkan di Bollywood adalah seperti Maqbool (2003) yang diadaptasikan daripada novel Macbeth, filem Omkara (2006) yang diadaptasikan daripada novel Orthello, filem Haidar (2014) yang diadaptasikan daripada novel Hamlet. Ketiga-tiga karya sastera berkenaan dihasilkan 
oleh pengkarya agung dalam dunia kesusasteraan iaitu William Shakespeare. Pada tahun 2010 filem Aisha telah dihasilkan daripada adaptasi novel Emma karya Jane Austen. Selain Bollywood, negara jiran kita iaitu Indonesia juga banyak menghasilkan filem yang diadaptasikan daripada karya sastera. Antaranya ialah filem Tenggelamnya Kapal Van Der Wijck yang diadaptasi daripada novel Tenggelamnya Kapal Van Der Wijck karya Hamka, filem Ayat-Ayat Cinta yang diadaptasikan daripada novel AyatAyat Cinta karya Habiburahmah El-Shirazy, filem Laskar Pelangi yang diadaptasikan daripada novel Laskar Pelangi karya Andrea Hirata dan banyak lagi. Begitu juga dengan pihak pembikin filem di negara-negara Asia Tenggara yang lain seperti Filipina dan Thailand yang banyak menghasilkan filem yang diadaptasikan daripada karyakarya sastera. Di Filipina misalnya terdapat beberapa filem yang dihasilkan daripada karya sastera seperti Maynila: Sa mga Kuko ng Liwanag yang diadaptasikan daripada novel The Claws of Light karya Edgardo Reyer, filem Bulaklak City Jail yang diadaptasikan dan filem Bata, Bata, Paano ka Ginawa yang kedua-duanya diadaptasi daripada novel dengan judul yang sama karya Lualhati Batista.

Pembikin filem di negara kita tidak terkecuali daripada menghasilkan filem yang diadaptasikan daripada karya sastera. Terdapat beberapa karya sastera terutamanya daripada genre novel telah diadaptasikan ke dalam bentuk filem di negara ini. Antaranya ialah filem Jogho (1999) yang diadaptasi daripada novel Juara karya S. Othman Kelantan, filem Ombak Rindu (2011) yang diadaptasikan daripada novel dengan tajuk yang sama karya Fauziah Ashaari, filem Tombiruo: Penunggu Rimba (2017) yang diadaptasi daripada novel dengan tajuk yang sama karya Ramlee Awang Murshid dan filem Pulang (2018) yang diadaptasi daripada novel dengan tajuk yang sama karya Lily Haslina Nasir. Selain filem-filem berkenaan terdapat beberapa filem lain yang turut diadaptasikan daripada karya sastera. Selain diadaptasikan ke dalam bentuk filem, terdapat juga karya-karya sastera diadaptasikan ke dalam pelbagai medium lain seperti pementasan teater, drama, telefilem dan juga filem pendek. Keadaan ini membuktikan betapa aktifnya aktiviti pengadaptasian karya-karya sastera ke dalam bentuk filem dan pelbagai media lain yang dilakukan oleh anggota masyarakat.

Berdasarkan kepada jumlah filem yang dihasilkan daripada adaptasi karya sastera yang begitu banyak tersebut telah membuka ruang yang lebih luas untuk pengembangan dunia kesusasteraan itu sendiri. Kemampuan karya-karya sastera untuk dihasilkan dalam bentuk baharu ini memperlihatkan bahawa bidang kesusasteraan adalah sebuah bidang ilmu yang bersifat fleksibel dan membolehkannya kekal relevan dan masih diterima oleh masyarakat di seantero dunia sehingga ke hari ini. Sifat fleksibel bidang kesusasteraan ini boleh dikesan apabila bidang ini boleh digabung jalin dengan pelbagai bidang ilmu yang lain seperti bidang perfileman, seni halus, drama pentas, permainan elektronik, dan sebagainya. Antara bidang yang sering menjadi perhatian dalam membincangkan sifat fleksibiliti bidang kesusasteraan adalah dalam bidang perfileman. Oleh itu, dalam penulisan ini, bakal dilakukan penelitian terhadap elemen-elemen adaptasi yang terkandung di dalam filem TPR. 


\subsection{Tinjauan Literatur}

Perbincangan berkenaan dengan elemen-elemen adaptasi yang terkandung di dalam filem adaptasi TPR telah dilakukan oleh beberapa sarjana dengan meneliti aspekaspek tertentu. Antaranya adalah melalui artikel yang dihasilkan oleh Hani Salwah Yaakup (2018) yang membincangkan perkara berkaitan dengan adaptasi novel ke filem. Menerusi artikelnya, beliau telah mengemukakan beberapa contoh filem yang telah diadaptasi di Malaysia. Penulisan beliau banyak menekankan kepada aspekaspek kepercayaan yang melingkari masyarakat di dalam teks dan filem adaptasi berkenaan. Fokus penelitian beliau tidak menjurus kepada aspek naratif dan aspek lain tetapi hanya memberi penekanan kepada aspek kepercayaan sahaja.

Sohaimi Abdul Aziz (2011) telah melakukan perbincangan berkenaan dengan adaptasi dalam filem Laskar Pelangi. Berdasarkan penelitian yang beliau lakukan, terdapat beberapa peringkat di dalam proses adaptasi filem berkenaan. Peringkat-peringkat tersebut dikategorikan kepada 4 iaitu peringkat naratif, peringkat verbal ke visual, peringkat enunciation dan peringkat keseluruhan. Keempat-empat peringkat berkenaan telah diterapkan di dalam penelitian filem adaptasi Laskar Pelangi yang membawa kepada hasil yang memperrlihatkan wujudnya hubungan yang akrab di antara kedua-dua karya berkenaan daripada karya asal (novel) kepada karya filem adaptasi.

Seterusnya, Nur Nafishah Azmi et. al. (2012) telah menghasilkan sebuah artikel yang membincangkan aspek kesetiaan dalam penghasilan filem adaptasi. Dalam kajian ini didapati, filem adaptasi yang dihasilkan daripada novel Ranjau Sepanjang Jalan karya Shahnon Ahmad masih lagi setia dengan teks asalnya. Perbincangan berfokus kepada penerapan aspek-aspek yang terkandung di dalam teks asal ke dalam filem adaptasi yang dihasilkan. Pihak pembikin filem didapati mengambil babak yang terkandung di dalam teks secara keseluruhannya tanpa mengubah idea asal penulis. Bahkan dialog yang digunakan adalah dialog asal yang terkandung di dalam teks. Jadi jelas bahawa perbincangan yang dilakukan di dalam penulisan artikel ini lebih menjurus kepada penelitian aspek kesetiaan dalam penghasilan filem adaptasi.

Selain itu, artikel yang ditulis oleh Nur Yuhanis Binti Mohd Nasir et. al. (2016) turut mengetengahkan berkenaan dengan filem adaptasi. Penekanan yang diberikan adalah terhadap elemen adaptasi yang terkandung di dalam kisah Puteri Saadong. Namun, penelitian elemen adaptasi yang dilakukan dengan meneliti suntikan kerja animasi dua dimensi (2D). Penelitian elemen adaptasi lebih bersifat teknikal kerana bersandarkan kepada proses pembangunan animasi $2 \mathrm{D}$ tersebut dengan memperincikan aspek pengekalan, pengguguran dan pengubahsuaian terhadap cerita animasi yang dihasilkan. Hasil kajian ini mendapati penggunaan animasi dalam penghasilan adaptasi juga boleh menarik minat masyarakat dan dapat mengembangkan karya warisan bangsa.

Mohamed Nazreen Shahul Hamid dan Md Salleh Yaapar (2015) juga telah membincangkan berkenaan dengan filem adaptasi. Penelitian mereka berfokus kepada teks Hikayat Merong Mahawangsa dengan memberikan penekanan kepada aspek naratif. Melalui artikel ini, mereka menghuraikan perbandingan filem Hikayat Merong Mahawangsa dengan teks asalnya dari pelbagai sudut seperti plot, watak, 
latar, gaya penulisan dan tema untuk menilai aspek persamaan dan perbezaan antara kedua-dua medium berkenaan. Penelitian ini bersandarkan kepada pendekatan yang telah diasaskan oleh Desmond dan Hawkes.

Seterusnya, Sohaimi Abdul Aziz (2014) juga telah mengetengahkan perbincangan berkaitan dengan aspek adaptasi dengan membandingkan dua buah karya iaitu filem Hikayat Merong Mahawangsa dan Teater Muzikal Siti Zubaidah. Berdasarkan penulisannya, beliau menerangkan aspek keindahan warisan budaya yang dimiliki oleh sesuatu bangsa untuk diketengahkan kepada khalayak ramai sebagai sebuah seni yang bernilai. Usaha beliau melalui penulisan artikel ini adalah ingin mengetengahkan betapa medium adaptasi boleh dimanfaatkan untuk menonjolkan aspek kebudayaan masyarakat yang sekian lama tersimpan di dalam teks sastera. Beliau menegaskan bahawa filem sebagai sebuah medium baharu untuk melestarikan warisan budaya.

Wan Hasmah Wan Teh (2015) dalam artikelnya membincangkan aspek definisi, kontroversi adaptasi dan kaedah adaptasi. Beliau secara umumnya ingin mengemukakan betapa aspek adaptasi perlu difahami dengan baik oleh pelbagai pihak terutamanya penulis karya sastera dan pihak pembikin filem. Beliau mengemukakan betapa penghasilan filem adaptasi amat berkesan dalam memberi kefahaman kepada khalayak pembaca. Melalui artikel ini, beliau juga membincangkan berkenaan dengan proses adaptasi sebagai sebuah usaha yang sangat baik dan membanggakan. Usaha tersebut adalah sebuah usaha yang sangat indah kepada pihak pembikin filem dapat menterjemahkan karya asal kepada satu media yang baru iaitu filem.

Nur Azliza Mohd Nor dan Nur Afifah Vanitha Abdullah (2017) telah mengemukakan perbincangan berkaitan dengan filem-filem adaptasi yang telah diarahkan oleh U-Wei Haji Shaari dengan mengambil kira aspek-aspek yang diberikan penekanan oleh beliau dalam menghasilkan filem adaptasi berkenaan. Hasil daripada kajian ini mendapati kebanyakan filem adaptasi yang dihasilkan oleh U-Wei Haji Shaari banyak menyentuh aspek-aspek feminisme. Aspek-aspek feminisme ini dijadikan sebagai tumpuan utama oleh beliau dengan memaparkan imej-imej wanita di dalam filem hasil arahannya. Keadaan ini memperlihatkan bahawa beliau banyak menerapkan pendekatan feminisme dalam menghasilkan filem adaptasi berkenaan berbanding dengan pendekatan-pendekatan lain. Secara keseluruhannya, kajian yang dilakukan oleh mereka telah memberikan gambaran tentang pendekatan yang menjadi tumpuan oleh U-Wei Haji Shaari dalam menghasilkan filem adaptasi.

Hani Salwah Yaakup (2018) pernah menghasilkan sebuah artikel yang membincangkan berkenaan dengan filem TPR. Fokus yang diberikan dalam penelitian tersebut adalah terhadap aspek-aspek kepercayaan masyarakat setempat yang dipaparkan di dalam filem berkenaan. Bagi menganalisis aspek berkenaan, aspek watak dan perwatakan serta aspek naratif diberikan penekanan untuk mengesan representasi kepercayaan yang diketengahkan oleh pihak pembikin filem berkenaan. Dapatan daripada kajian ini memperlihatkan representasi kepercayaan masyarakat setempat yang dipaparkan di dalam filem adalah kurang tepat dan tidak diberikan perincian yang sewajarnya. 
Selain itu, Nur Aifaa Nabilah Mohd Rosdi et. al. (2020) turut membuat penelitian terhadap filem TPR. Dalam penelitian tersebut, mereka meneliti pengadaptasian filem TPR dari aspek naratif dengan menggunakan teori intertekstualiti daripada Julia Kristeva. Hasil daripada penelitian berkenaan, didapati bahawa terdapat perbezaan dari proses naratif adaptasi iaitu dari aspek latar, plot, dan watak. Keadaan ini secara tidak langsung menunjukkan bahawa penelitian dalam kajian ini berfokus kepada aspek naratif dan tidak menyentuh mengenai aspek-aspek luaran seperti yang bakal dilaksanakan dalam kajian ini.

Berdasarkan kepada tinjauan literatur yang telah dilakukan terhadap kajjian-kajian lepas berkenaan, didapati belum ada kajian yang dilaksanakan mengkhusus kepada filem TPR. Kajian-kajian tersebut berfokus kepada filem-filem adaptasi yang lain dan menerapkan pendekatan-pendekatan yang lebih memfokuskan kepada aspek naratif. Manakala, penelitian dalam kajian ini pula lebih memberikan penekanan kepada aspek adaptasi bersandarkan kepada pendekatan yang dikemukakan oleh Linda Hutcheon (2006). Aspek-aspek yang bakal diberikan fokus pula bukan terhadap penelitian elemen naratif tetapi elemen yang menyebabkan berlakunya proses adaptasi berkenaan. Oleh itu, keadaan ini telah membuka ruang penelitian kepada penghasilan analisis terhadap penulisan ini.

Kajian berkaitan dengan pendekatan adaptasi adalah sebuah kajian yang banyak mendapat perhatian daripada kalangan penyelidik kesusasteraan. Walaupun sedemikian, kajian yang meneliti filem adaptasi TPR masih kurang dilaksanakan khususnya mengaplikasikan kaedah adaptasi Linda Hutcheon (2006). Oleh hal yang sedemikian, penelitian dalam penulisan ini berusaha untuk mengisi kekosongan berkaitan dengan kajian terhadap filem ini. Filem TPR adalah sebuah filem adaptasi Malaysia yang perlu diberi perhatian kerana banyak aspek tempatan yang terkandung di dalamnya dan masih belum diterokai dengan menyeluruh. Aspek adaptasi yang bakal dilaksanakan diharap dapat mempelbagaikan lagi kajian berkaitan dengan filem adaptasi di negara ini dan seterusnya diharap dapat menarik minat pihak pembikin filem untuk menghasilkan lebih banyak filem adaptasi bagi memenuhi permintaan industri filem di negara ini secara khusus. Malahan turut diharapkan juga penghasilan filem adaptasi tempatan dapat menembusi pasaran antarabangsa dan secara tidak langsung dapat mengetengahkan kepelbagaian budaya dan warisan yang terkandung di dalam karya kesusasteraan tanah air di peringkat global.

\subsection{Metodologi}

Penelitian dalam penghasilan artikel ini bersandarkan kepada kaedah kualitatif dengan melaksanakan beberapa tinjauan terhadap kajian yang telah dilakukan oleh pengkaji terdahulu berkaitan dengan elemen adaptasi. Usaha untuk melaksanakan tinjauan terhadap kajian terdahulu ini dilakukan dengan beberapa kaedah seperti kaedah analisis dokumen. Bagi melaksanakan kaedah berkenaan, pelbagai sumber daripada perpustakaan terutamanya Perpustakaan Universiti Malaysia Kelantan, Perbadaan Perpustakaan Negeri Kelantan, Perpusatakaan Hamzah Sendut Universiti Sains Malaysia dan Perpustakaan Dewan Bahasa dan Pustaka Wilayah Timur. Bahan-bahan daripada perpustakaan berkenaan seperti buku, jurnal dan prosiding bakal dijadikan sebagai sumber untuk dianalisis. 
Seterusnya, melalui kaedah kualitatif ini juga, penelitian secara terperinci dilakukan terhadap teks yang dikaji iaitu novel TPR karya Ramlee Awang Murshid dan filem adaptasi dengan tajuk yang sama arahan Seth Larney yang diterbitkan pada tahun 2017 dan dibarisi pelakon-pelakon hebat seperti Zul Ariffin, Nabila Huda, Farid Kamil, Datuk M. Nasir, Faizal Hussein dan ramai lagi. Kandungan ceritanya mengisahkan seorang lelaki yang tidak berwajah manusia yang bernama Tombiruo dan mempunyai misi untuk mencari pembunuh ayahnya, Pondolou. Kemunculan Amiruddin yang memburu Tombiruo untuk membela kematian isterinya. Wan Suraya merupakan seorang wartawan yang mempunyai semangat yang berani untuk mengupas kebenaran di sebalik kejadian yang menimpa Salina dan ayahnya yang menjadi mangsa dalam kemalangan. Karya ini telah membuka kisah suka dan duka yang membentuk sebuah ikatan kekeluargaan.

Proses pembacaan novel dilakukan terlebih dahulu bagi membolehkan pengkaji memahami aspek-aspek tekstual yang terdapat di dalam novel berkenaan. Setelah itu, proses meneliti filem dilakukan dengan menonton filem bagi mengesan elemenelemen adaptasi yang terkandung di dalamnya. Penelitian dilakukan terhadap keduadua medium ini bagi membolehkan elemen adaptasi diperhalusi dengan sebaiknya. Usaha untuk meneliti elemen-elemen adaptasi ini berteraskan kepada pendekatan adaptasi yang dipelopori oleh Linda Hutcheon dengan menerapkan elemen sumber dan cara adaptasi, tujuan adaptasi, kumpulan atau penonton sasaran dan konteks. Empat elemen berkenaan bakal dijadikan sebagai teras kepada penelitian artikel ini.

\subsection{Analisis dan Perbincangan}

Pendekatan adaptasi yang dipelopori oleh Linda Hutcheon adalah sebuah pendekatan yang bersesuaian untuk meneliti elemen adaptasi yang terkandung di dalam filem $T P R$. Namun, sebelum perbincangan lebih lanjut berkenaan dengan aspek-aspek adaptasi yang terkandung di dalam TPR, perbincangan terlebih dahulu dimulakan dengan memahami beberapa istilah penting dalam penelitian ini. Antara istilah tersebut ialah kesusasteraan yang secara asasnya adalah bidang ilmu yang berpaksikan kepada penghasilan karya-karya kreatif dalam bentuk lisan dan tulisan dan wujud dalam pelbagai genre. Perkara ini telah dijelaskan oleh Md Salleh Yaapar et. al. (2015) yang mentakrifkan kesusasteraan sebagai karya bersifat imaginatif yang tampil dalam bentuk prosa, puisi dan drama sama ada berbentuk sastera bertulis ataupun lisan. Pada, kesusasteraan mencakupi karya sastera dan bukan sastera, tetapi kini cakupannya lebih meluas kerana kesusasteraan juga merujuk kepada pelbagai bentuk karya seperti undang-undang, falsafah, sejarah, roman, kitab, adab dan sebagainya. Sifat fleksibel yang dimiliki oleh bidang kesusasteraan membolehkan bidang ini bercambah secara vertikal dan horizontal dengan pelbagai bidang ilmu yang lain. Antaranya adalah dalam bidang perfileman. Pekara ini menjadikan ruang untuk perkembangan bidang kesusateraan lebih meluas dan semakin diterima oleh anggota masyarakat. Menurut Totawad Nagnath Ramrao (2016), film is such a field which was more related to photography and painting in the beginning. Ringkasnya, filem adalah sebuah medium penghasilan sesebuah penceritaan yang menggunakan elemen fotografi dan lukisan yang turut disertakan dengan kesan bunyi bagi membolehkan khalayak menerima kesan secara audio dan juga visual. 
Istilah kedua yang perlu difahami juga ialah filem. Sifat fleksibel yang dimiliki oleh bidang kesusasteraan membolehkan bidang ini bercambah secara vertikal dan horizontal dengan pelbagai bidang ilmu yang lain. Antaranya adalah dalam bidang perfileman. Pekara ini menjadikan ruang untuk perkembangan bidang kesusasteraan lebih meluas dan semakin diterima oleh anggota masyarakat. Menurut Totawad Nagnath Ramrao (2016), film is such a field which was more related to photography and painting in the beginning. Ringkasnya, filem adalah sebuah medium penghasilan sesebuah penceritaan yang menggunakan elemen fotografi dan lukisan yang turut disertakan dengan kesan bunyi bagi membolehkan khalayak menerima kesan secara audio dan juga visual

Istilah yang ketiga pula ialah filem adaptasi. Berdasarkan pengertian konsep kesusasteraan dan filem yang telah dikemukakan, dapat dirumuskan sebuah pemahaman terhadap hubungan yang terjalin antara kedua-dua bidang berkenaan dengan menggunakan konsep adaptasi. Konsep adaptasi adalah sebuah proses penghasilan sesebuah filem dengan menyunting sesebuah karya sastera dan dihasilkan dalam satu bentuk baharu iaitu filem. Proses adaptasi merupakan sebuah proses yang diambil daripada teori adaptasi untuk menghasilkan karya filem daripada bahan sastera. Menurut Gordon E-Slethoug (2014) teori adaptasi merupakan intertextuality atau hubungan antara teks dan filem. Pandangan beliau jelas memperlihatkan bahawa adaptasi adalah sebagai sebuah proses yang menghubungkan antara dua medium iaitu teks dan filem dengan menggunakan konsep intertekstualiti. Pandangan ini turut disokong oleh Desmond \& Hawkes (2005) yang menyatakan bahawa,

Intertextuality is the term used to suggest that texts refer to or cite other works. Film adaptations are by definition intertextual since they refer to an antecedent text.

Selain itu, Md Salleh Yaapar et. al. (2015) juga mentakrifkan adaptasi sebagai penyesuaian dengan keadaan yang baharu atau berbeza. Penyesuaian melibatkan penyusunan semula keseluruhan atau sebahagian karya daripada suatu bahasa, budaya, medium atau genre kepada bahasa, budaya, medium atau genre yang lain. Adaptasi yang melibatkan bahasa dan budaya ialah karya terjemahan dan saduran. Adaptasi yang melibatkan medium dan genre ialah novel atau cerpen kepada filem atau televisyen, atau daripada novel kepada drama.

Berdasarkan kepada pemahaman terhadap istilah-istilah berkenaan, penelitian lanjut boleh diberikan kepada aspek adaptasi itu sendiri. Melalui pendekatan adaptasi yang dikemukakan oleh Hutcheon (2006), terdapat empat elemen yang bakal diaplikasikan untuk meneliti filem TPR. Penelitian ini akan memberikan fokus kepada empat aspek utama seperti Rajah 1 berikut, 


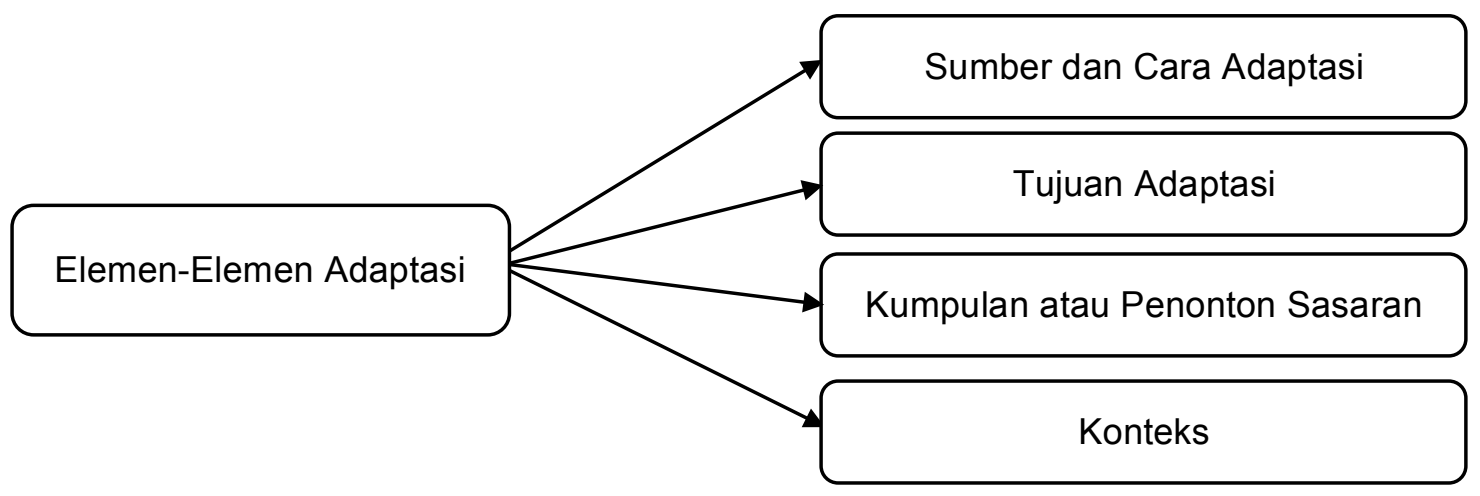

Rajah 1: Elemen-Elemen Adaptasi Linda Hutcheon (2006)

\subsection{Sumber dan Cara Adaptasi}

Berdasarkan karya-karya yang diadaptasi, karya asli adalah sebagai pemalar untuk dijadikan panduan bagi pembentukan sebuah karya yang baharu. Pemalar bermaksud suatu kuantiti yang mempunyai nilai sama. Perkara ini membuktikan bahawa perlaksanaan karya adaptasi perlu melalui proses asas elemen adaptasi seperti tema, persoalan, watak, latar dan simbol. Dalam konteks ini novel adalah pemalar bagi penghasilan filem adaptasi. Hutcheon (2006) menegaskan dalam proses adaptasi, perubahan terhadap watak juga dapat mempengaruhi pembentukan retorik dan memberi kesan estetika penceritaan atau persembahan yang baharu. Berdasarkan filem TPR, tema seperti kasih sayang, kekeluargaan, persahabatan, perjuangan dapat dilihat jelas melalui perwatakan watak. Sebagai contohnya, tema kasih sayang dapat dilihat melalui watak Pondolou yang bertindak melindungi anak jagaannya iaitu Tombiruo ketika diserang oleh orang kampung. Tambahan lagi, perasaan emosi penonton terus terusik semasa peristiwa rusuhan di dalam kawasan kampung yang telah mengorbankan Pondolou. Perbuatan tersebut telah memberi kesan emosi kepada penonton yang merasakan emosi kasih sayang seorang bapa terhada anaknya.

Seterusnya, penghasilan adaptasi juga melibatkan pemindahan maklumat daripada novel ke filem. Proses penghasilan karya adalah berbeza kerana melalui penulisan novel tidak mempunyai kekangan masa namun di dalam penghasilan novel terdapat kekangan masa yang perlu dipantau. Malahan itu, konsep penulisan adalah sama seperti konsep asas penghasilan novel iaitu mempunyai plot, watak dan perwatakan, latar dan sebagainya tetapi dipersembahkan dengan penerapan media. Penerapan media merupakan penggunaan teknologi bagi menghasilkan satu gaya persembahan yang unik dan berbeza dengan novel. Sebagai contoh, dalam filem TPR telah melalui proses pemindahan maklumat novel ke filem. Pengarah dan kumpulan produksi telah menggarap idea utama di dalam novel tersebut untuk dijadikan sebuah filem yang berkualiti. Proses tersebut akan mengubah keseluruhan novel untuk disesuaikan dengan penghasilan filem. Perkara tersebut telah disokong oleh Hutcheon (2006) yang menyatakan pendekatan yang boleh digunakan untuk mengadaptasi adalah dengan mengubah fokus atau sudut pandang cerita, namun perubahan sebegini boleh menjurus kepada rombakan 
cerita secara besar-besaran. Secara umumnya, penghasilan adaptasi melalui perubahan daripada novel fizikal ke bentuk baharu iaitu filem yang dilengkapi dengan visual, audio dan elemen lain. Lazimnya, penghasilan filem memerlukan peralatan lengkap seperti kamera, mounting equipment, viewfinder, lens dan video tape recording. Peralatan ini adalah kunci kejayaan sesebuah filem sama ada filem adaptasi atau sebaliknya.

Jika melihat kepada penghasilan novel TPR, pembaca dapat memberi pandangan melalui sudut pandangan imaginasi. Namun, pancaindera manusia adalah terbatas untuk membayangkan secara keseluruhan mengenai peristiwa yang digambarkan. Pendedahan terhadap media telah mengisi kelompongan tersebut. Penghasilan filem adaptasi yang dilengkapi dengan pergerakan, kesan bunyi serta gambaran yang jelas mengenai peristiwa yang dipaparkan. Keadaan ini ditampilkan di dalam filem TPR dengan memaparkan babak Tombiruo di dalam rumah miliknya yang terletak di atas sebatang pokok. Secara logiknya, perkara tersebut sukar dilakukan oleh manusia biasa. Namun dengan bantuan teknologi seperti computer-generated imagery (CGI) telah membantu penonton untuk mendapat gambaran yang lebih luas.

Proses menukar novel kepada bentuk filem bukanlah perkara mudah dan mengambil masa yang singkat. Pihak produksi perlu memberi perhatian sepenuhnya terhadap sumber novel asli yang digunakan bagi proses adaptasi. Hal ini demikian kerana penghasilan filem adaptasi adalah bergantung terhadap penerapan sumber asli yang digunakan. Pembaca atau penonton akan membuat penilaian terhadap keaslian cerita yang dihasilkan. Malahan itu, pemendekan atau pemadatan novel dalam filem yang berdurasi kurang dua jam memerlukan plot cerita tidak membosankan. Penerapan elemen-elemen asas penghasilan filem sangat dititiberatkan. Filem adaptasi yang baik adalah mempunyai segala ciri-ciri keistimewaan adaptasi untuk menarik minat pembaca novel khususnya bagi merasai pengalaman baharu yang sukar diperolehi melalui proses pembacaan.

\subsection{Tujuan Adaptasi}

Penghasilan filem adaptasi bukanlah bersifat kosong dan perbuatan yang tidak memberi sebarang faedah. Namun, penghasilan filem tersebut mempunyai tujuan yang jelas terhadap industri filem di negara Malaysia. Adaptasi juga telah memberikan kesan terhadap bidang ekonomi, budaya, undang-undang serta peribadi.

Ekonomi adalah ilmu bukan penggelaran, pengagihan, penggunaan barangbarang dan perkhidmatan. Perkara ini telah dinyatakan oleh Hutcheon (2006) bahawa "from another economic angle, expensive collaborative art forms like operas, musicals, and films are going to look for safe bets with a ready audience-and that usually means adaptations. They are also going to seek ways to expand the audience for their "franchise", of course though they have not been in the habit of thinking about it in quiet those terms." Berdasarkan pandangan tersebut, ternyata bahawa filem TPR merupakan sebuah filem adaptasi yang telah mendapat sambutan hangat daripada peminatnya sendiri 
yang telah memberikan sumbangan besar kepada aspek ekonomi dalam perfileman. Buktinya dapat dilihat melalui jumlah kutipan keseluruhan filem tersebut yang melebihi RM 7 juta (finas.gov.my). Data daripada FINAS juga menunjukkan bahawa filem TPR berada di kedudukan ke-25 daripada keseluruhan filem Malaysia yang mempunyai kutipan paling banyak yang dapat dilihat melalui carta berikut,

Jadual 1: TPR Berada di Kedudukan Ke-25 Paling Banyak Kutipan

(Sumber: finas.gov.my)

\begin{tabular}{|c|c|c|c|c|c|c|c|}
\hline 20. & MISTERI DILAILA & SYAFIQ YUSOF & $\begin{array}{l}\text { SKOP PRODUCTION SDN. BHD. / ASTRO } \\
\text { SHAW SDN. BHD. }\end{array}$ & SERAM & 9.44 & 2019 & 80 \\
\hline 21. & $\begin{array}{l}\text { HANTU } \\
\text { BONCENG }\end{array}$ & AHMAD IDHAM & EXCELLENT PICTURES SDN. BHD. & KOMEDI & 8.54 & 2011 & 68 \\
\hline 22. & NGANGKUNG & $\begin{array}{l}\text { ISMAIL BOB } \\
\text { HASHIM }\end{array}$ & MIG PRODUCTION SDN. BHD. & KOMEDI & 8.18 & 2010 & 59 \\
\hline 23. & KONGSI & FARID KAMIL & MIG PRODUCTION SDN. BHD. & AKSI & 8.09 & 2011 & 87 \\
\hline 24. & KHURAFAT & SYAMSUL YUSOF & SKOP PRODUCTIONS SDN. BHD. & SERAM & 8.08 & 2011 & 66 \\
\hline 25. & $\begin{array}{l}\text { TOMBIRUO : } \\
\text { PENUNGGU } \\
\text { RIMBA }\end{array}$ & SETH LARNEY & ASTRO SHAW SDN. BHD. & AKSI & 7.97 & 2017 & 62 \\
\hline 26. & $\begin{array}{l}\text { HANTU KAK } \\
\text { LIMAH BALIK } \\
\text { RUMAH }\end{array}$ & MAMAT KHALID & TAYANGAN UNGGUL SDN. BHD. & KOMEDI & 7.90 & 2010 & 46 \\
\hline 27. & $\begin{array}{l}\text { BIKERS KENTAL } \\
2\end{array}$ & $\begin{array}{l}\text { MOHD HELMI } \\
\text { YUSOF }\end{array}$ & MRB NETWORK SDN. BHD. & KOMEDI & 7.68 & 2019 & 88 \\
\hline 28. & ADNAN SEMPIT & AHMAD IDHAM & MIG PRODUCTION SDN. BHD. & KOMEDI & 7.66 & 2010 & 61 \\
\hline 29. & $\begin{array}{l}\text { AH BENG THE } \\
\text { MOVIE : THREE } \\
\text { WISHES (Kantonis) }\end{array}$ & SILVER CHUNG & THE FILM ENGINE SDN. BHD. & DRAMA & 7.55 & 2012 & 100 \\
\hline 30. & WIRA & ADRIEN TEH & $\begin{array}{l}\text { MULTIMEDIA ENTERTAINMENT SDN. } \\
\text { BHD. }\end{array}$ & AKSI & 7.29 & 2019 & 90 \\
\hline
\end{tabular}

Nilai tersebut bukanlah perkara yang mudah untuk dicapai dalam industri filem di Malaysia. Namun, kredibiliti penulis novel yang berpengalaman hampir 20 tahun telah menjadi penarik utama. Jelaslah, penghasilan filem adaptasi telah membantu dalam meningkatkan penjanaan ekonomi dalam kalangan penggiat seni.

Selain itu, Hutcheon (2006) turut menegaskan bahawa untuk menghasilkan sebuah filem adaptasi, pihak terbabit perlu memahami sepenuhnya isu perundangan. Isu perundangan yang sering menjadi tumpuan adalah mengenai isu pemilikan atau hak cipta. Berdasarkan Akta Hakcipta 1987, hak cipta merupakan hak istimewa yang diberikan melalui pelaksanaan undang undang untuk mengawal penggunaan karya. Jenis-jenis karya yang layak mendapat perlindungan adalah seperti karya sastera, karya muzik, karya seni, filem, rakaman bunyi siaran dan karya terbitan. Perbadanan Kemajuan Filem Nasional Malaysia (FINAS) telah menjalinkan kerjasama dengan penulis novel iaitu Ramlee Awang Murshid bagi mengangkat novel tersebut ke layar perak. Kerjasama tersebut bertujuan untuk menjaga hak samada penulis novel, penulis skrip filem atau semua pihak yang terlibat dalam penghasilan filem adaptasi TPR.

Filem adaptasi TPR juga telah membawa penonton mengalami proses merentas budaya dalam masyarakat Kadazan Dusun di Sabah. Budaya adalah set khas kerohanian, kebendaan, intelektual dan ciri emosi masyarakat 
atau kelompok sosial (Mohamad Zain Musa \& Nik Hassan Suhaimi Nik Abdul Rahmah, 2010). Memetik pernyataan Hutcheon (2006) bahawa adaptasi membolehkan nilai budaya ditransformasikan ke dalam suatu bentuk persembahan yang baharu. Berdasarkan novel TPR, penulis novel memberikan peluang kepada pembaca untuk merasai pengalaman masyarakat di negeri Sabah dalam etnik Kadazan Dusun. Selepas diadaptasi, penonton dapat merasai, melihat serta mengalami pengalaman mengenai masyarakat di Sabah. Sebagai contohnya, perkataan Tombiruo merupakan perkataan daripada etnik Kadazan Dusun yang membawa maksud kepada roh atau hantu. Tombiruo juga merupakan mitos yang menjadi legenda dalam kalangan masyarakat di kawasan pedalaman Keningau. Oleh itu, adaptasi filem telah menyelitkan unsur budaya dalam penghasilan karya mereka. Unsur budaya tersebut telah memberikan kesan terhadap emosi penonton serta menimbulkan perasaan ingin tahu mengenai budaya baharu di negara ini.

Adaptasi juga bertujuan untuk memberikan pandangan peribadi pemilik karya melalui rombakan karya asal, perspektif serta pandangan. Penulis novel TPR memberikan maklum balas selepas tayangan filem dengan menyatakan bahawa impian beliau untuk merealisasikan permintaan peminatnya melihat tulisan tangannya ke layar perak menjadi realiti. Beliau juga menasihati agar peminat karya tulisannya tidak membandingkan antara novel dan filem kerana proses adaptasi bukanlah perkara yang mudah. Wan Hasmah Wan Teh (2013) menyatakan bahawa pengadaptasian bukanlah usaha untuk memastikan filem itu setia pada teks yang menjadi sumbernya. Tetapi ia merupakan satu interpretasi semula di samping mengekalkan semangat karya tersebut. Tambahan lagi, selepas filem TPR novel filem adaptasi tersebut telah dicetak melebihi 20 kali. Perkara tersebut merupakan satu kebanggaan buatRamlee Awang Mursyid sebagai penulis novel.

\subsection{Kumpulan atau Sasaran Penonton}

Penonton sasaran merupakan fokus utama terhadap penghasilan sesebuah filem adaptasi. Lazimnya, kumpulan fokus utama ini adalah kelompok yang menggemari karya- novel yang akan diadaptasi. Sebelum penerbitan filem TPR mereka telah menantikan novel tersebut untuk diangkat ke layar perak. Penghasilan filem adaptasi tersebut amat dinanti-nantikan oleh peminatpeminat karya Ramlee Awang Murshid. Kelompok penonton sasaran juga merupakan salah satu punca utama kejayaan bagi filem adaptasi di layar perak. Melalui adaptasi jurang yang terdapat di dalam novel dapat memenuhi impian pembaca setia novel. Perkara ini dinyatakan oleh M. Fazmi Hisham (2016) bahawa karya novel selalunya diadaptasi ke dalam bentuk filem kerana mendapat tempat di hati pembaca. Pelbagai bentuk tema atau genre untuk dibaca dan menonton apabila sudah diterbitkan ke dalam bentuk filem. Novel yang diadaptasi adalah bertujuan komersil, justeru biasanya ia sudah pun mendapat tempat di hati pembaca.

Adaptasi merupakan sebuah proses menghasilkan semula karya sastera yang boleh dilakukan dalam pelbagai variasi seni persembahan untuk menarik minat kumpulan sasaran. Malahan itu, adaptasi juga dapat dipersembahkan 
melalui seni teater, pementasan, drama dan tidak hanya cenderung kepada bentuk filem. Terdapat pelbagai faktor yang mempengaruhi sesebuah kelompok penonton sasaran. Faktor tersebut adalah seperti jantina, umur, latar belakang serta tahap pendidikan (Hutcheon, 2006). Berdasarkan penelitian kepada latar belakang penulis novel itu sendiri iaitu Ramlee Awang Murshid, beliau mempunyai jumlah peminat yang tersendiri yang dapat dilihat melalui laman sosial beliau. Antaranya adalah melalui facebook dan intagram. Sebagai contoh laman Facebook Kelab Peminat Ramlee Awang Murshid (RAMCF) dan juga laman Instagram milik penulis sendiri yang diikuti lebih daripada 14 ribu pengikut (Rajah 2 dan 3).

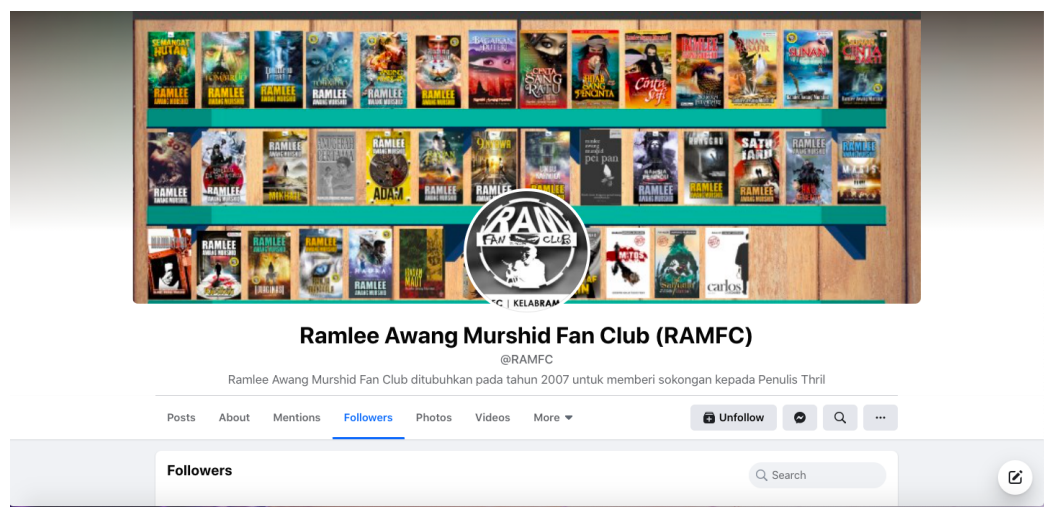

Rajah 2: Tangkap Layar Laman Facebook Ramlee Awang Murshid Fan Club (RAMFC)

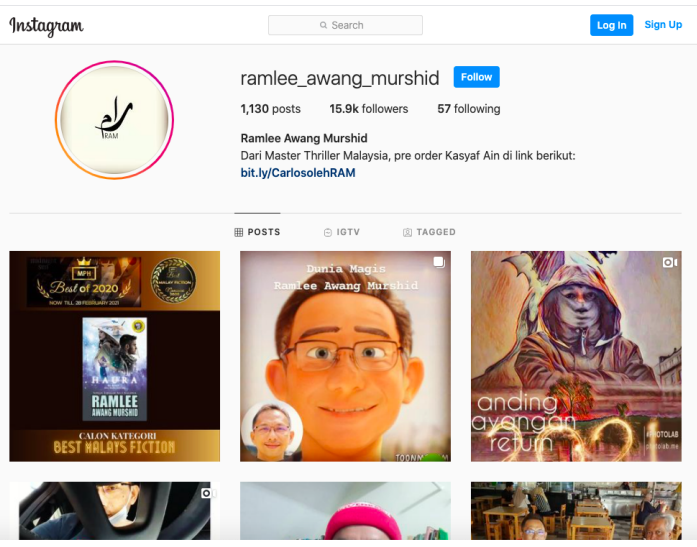

Rajah 3: Tangkap Layar Laman Instagram Ramlee Awang Murshid

Berdasarkan jumlah pengikut penulis karya melalui media sosial berkenaan memperlihatkan bahawa beliau merupakan seorang penulis yang mempunyai pengaruh yang kuat dalam kalangan peminatnya. Keadaan ini seterusnya turut memberi impak kepada penerimaan terhadap filem TPR yang diadaptasikan daripada novel beliau. Berdasarkan filem TPR, kumpulan sasaran penonton adalah lebih cenderung kepada golongan lelaki dan perempuan yang telah 
dewasa. Hal ini demikian kerana novel asal filem adaptasi ini bertemakan thriller. Namun, novel tersebut tidak hanya terikat kepada unsur ganas kerana penulis novel telah menambah unsur percintaan di dalam novel tersebut. Malahan itu, filem ini juga menerapkan unsur kekeluargaan yang utuh untuk memberikan penonton merasai pengalaman berkasih sayang. Perkara tersebut dalam dilihat melalui petikan babak filem TPR.

Seterusnya, adaptasi juga memberi kebaikan terhadap bidang pendidikan terutamanya golongan pendidik, ilmuwan serta pelajar. Hal ini demikian kerana adaptasi merupakan sebuah karya sastera yang telah mengalami proses perkembangan daripada bentuk tulisan kepada bentuk digital. Perkara tersebut telah membantu menonjolkan tahap intelektual pengkarya bagi menghasilkan sebuah filem adaptasi yang menepati cita rasa masyarakat moden kini. Penggunaan teks sastera bukan sahaja memberi pendidikan namun dapat membentuk masyarakat yang lebih berwibawa.

\subsection{Konteks}

Konteks bermaksud keseluruhan keadaan atau latar belakang tertentu yang ada kaitannya atau dapat dihubungkan dengan sesuatu. Adaptasi mendefinisikan konteks sebagai batasan yang mempengaruhi inti pati mencorakkan suatu persembahan adaptasi (Nur Yuhanis Mohd Nasir et. al., 2016). Perkara tersebut merupakan batasan yang dipengaruhi oleh perubahan masa, zaman atau ekonomi. Hutcheon (2006) menegaskan bahawa suatu karya adaptasi dilingkungi dengan batas waktu, masa, masyarakat dan budaya yang memberi identiti pada kandungannya. Elemen konteks diberi penekanan di dalam penghasilan filem adaptasi agar filem yang dihasilkan mempunyai persamaan dengan karya asal meskipun telah melalui pelbagai proses adaptasi.

Elemen konteks mengandungi format bahan dan material yang digunakan bagi memberi pengaruh kepada penghasilan filem adaptasi. Format merupakan gaya serta susunan sesuatu rancangan penerbitan yang dipersembahkan. Lazimnya, format berfungsi untuk memformatkan, menyediakan mengikut garis panduan yang telah ditetapkan supaya kelihatan lebih teratur. Filem TPR telah menggunakan novel TPR sebagai format bahan dan material bagi mengadaptasi filem. Kejayaan filem adaptasi adalah bergantung kepada penghasilan skrip yang baik mengikut acuan karya namun terdapat unsur penambahan dan pengguguran. Jika melihat kepada fungsi awal novel adalah sebagai bahan bacaan sahaja namun kemunculan teknologi telah membantu pembaca untuk merasai kemajuan dalam bentuk filem.

Seterusnya, bahasa juga dikategorikan dalam elemen konteks seperti yang dicadangkan oleh Hutcheon (2006). Fungsi bahasa adalah sebagai alat komunikasi bagi perhubungan. Perubahan bahasa adalah disebabkan latar masyarakat, latar masa serta latar politik kelompok masyarakat. Berdasarkan filem TPR, bahasa Kadazan Dusun telah digunakan dalam beberapa babak. Antaranya adalah semasa Tuan Berham membuat persidangan media di dalam sebuah kampung di Keningau dan babak 
kedua semasa Monsiroi meluahkan rahsia mengenai Ejim dan Amiruddin yang telah lama disimpan. Melalui penggunaan bahasa masyarakat KadazanDusun, penonton dapat menjiwai penceritaan di dalam filem adaptasi dengan lebih baik. Oleh hal yang sedemikian, elemen konteks juga perlu diambil kira dalam penghasilan filem adaptasi bagi menjamin kualiti serta penerimaan masyarakat terhadap filem yang dihasilkan.

\subsection{Kesimpulan}

Secara keseluruhannya, penelitian terhadap elemen adaptasi di dalam filem TPR memperlihatkan bahawa terdapat empat elemen adaptasi yang dapat dikesan di dalam penghasilan filem berkenaan. Elemen-elemen tersebut berjaya diterapkan dengan baik oleh pihak pembikin filem dan berjaya ditonjolkan untuk tatapan khalayak. Elemenelemen berkenaan adalah asas utama yang boleh dilihat dalam meneliti filem TPR dengan bersandarkan kepada pendekatan adaptasi oleh Hutcheon. Elemen-elemen tersebut dikesan dalam beberapa babak dan peristiwa yang dipaparkan di dalam filem adaptasi berkenaan yang menjadi pemangkin kepada perasaan penonton yang menonton filem tersebut. Diharapkan dengan perbincangan yang telah dilakukan dapat memberikan gambaran tentang aspek-aspek yang terkandung di dalam filem TPR melalui sudut pandang elemen adaptasi oleh Hutcheon. Diharapkan juga penelitian dalam penghasilan artikel ini dapat dijadikan sebagai rujukan dan dapat dikembangkan untuk mempelbagaikan lagi sudut pandang dalam dunia kesusasteraan terutamanya dalam dunia kesusasteraan di Malaysia.

\section{Rujukan}

Desmond, J. M. \& Hawkes, P. (2005). Adaptation: Studying Film and Literature. Boston, USA: Mc-Graw Hill Education.

E-Slethough, G. (2014). Adaptation Theory and Criticism. New York, USA: Bloomsburry Publishing Inc.

Hani Salwah Yaakup (2018). "Tombiruo: Adaptasi Novel ke Filem dan Representasi Kepercayaan Setempat. Jurnal Komunikasi Jilid 34 (2) 2018, 323-337

Hutcheon, L. (2006). A Theory of Adaptation. New York, USA: Routledge.

Kinney, M. E. et. at., (2013). Linda Hutcheon's A Theory of Adaptation, by Linda Hutcheon. Critical Voices. The University of Guelph Book Review Project.

M. Fazmi Hisham (2016). "Di Mana Novel Sastera dalam Filem dan Drama Tempatan?”. Berita Harian Online.

McFarlane, B. (1996). Novel to Film: An Introduction to the Theory of Adaptation. New York, USA: Clarendon Press.

Md Salleh Yaapar et. al. (2015). Kamus Kesusasteraan. Kuala Lumpur, Malaysia: Dewan Bahasa dan Pustaka. 
Mohamad Zain Musa \& Nik Hassan Shuhaimi Nik Abdul Rahman. "Peranan Budaya dalam Mempromosikan Keharmonian di Asia Tenggara. Jurnal Terjemahan Alam dan Tamadun Melayu Vol 1, No. 2 (2010), 183-189

Mohamed Nazreen Shahul Hamid \& Md. Salleh Yaapar (2015). Adaptasi Teks Hikayat Merong Mahawangsa Kepada Filem: Analisis Perbandingan Unsur Naratif. Jurnal Antarabangsa Dunia Melayu, 8 (2), 1675-6460

Nur Aifaa Nabilah Mohd Rosdi et. al. (2020). "Proses Transformasi Naratif Daripada Novel ke Filem Dalam Tombiruo: Penunggu Rimba (2017". Jurnal Melayu Isu Khas Disember 2020.

Nur Azliza Mohd Nor \& Nur Afifah Vanitha Abdullah (2019). Sisterhood Political Solidarity dalam Black Widow-Wajah Ayu (1994) Arahan U-Wei Haji Shaari. Jurnal Melayu, 18 (1), 16757513

Nur Nafisah Azmi et. al. (2012). Kesetiaan kepada Teks: Dari Novel ke Filem Ranjau Sepanjang Jalan. Persidangan Shahnon Ahmad Salam Sastera, Media dan Budaya.

Nur Yuhanis Binti Mohd Nasir et. al. (2016). Animasi Cerita Bangsawan Puteri Saadong: Adaptasi Teks dan Persembahan. MANU: Jurnal Pusat Penataran IImu dan Bahasa, 23, 1511-1989

Ramlee Awang Murshid (2007). Tombiruo: Penunggu Rimba. Shah Alam, Malaysia: Alaf 21 Sdn. Bhd.

Ramrao, T. N. (2016). Film and Literature: A Review. International Journal of Multidiciplinary Research, 2 (9), 2395-6968

Wan Hasmah Wan Teh (2013). "Adaptasi: Definisi, Kontroversi dan Kaedah" dlm. Sastera dalam Budaya dan Media. Penang, Malaysia: Penerbit Universiti Sains Malaysia.

Wan Hasmah Wan Teh (2015). Proses Adaptasi: Kajian Lapan Karya Terpilih dari Malaysia dan Indonesia. The Doctoral Research Abstracts, 7 (7)

Sohaimi Abdul Aziz (2011). "Laskar Pelangi: Satu Penelitian Adaptasi Novel ke Filem". Jurnal Kemanusiaan Vol 19., No.1 (2011), 35-52

Sohaimi Abdul Aziz (2014). Dahsyatnya Kesusasteraan Memerihalkan Kehidupan. Penang, Malaysia: Penerbit Universiti Sains Malaysia.

https://www.finas.gov.my/en/industry-information/top-50-feature-film/ (akses: 7 Februari 2021) 